\title{
Effects of Changes in Water Use on Rural Landscape Integrity: Tortum Lake Watershed, Turkey
}

\author{
ILKER ANGIN $^{1}$ \& FARIS KARAHAN ${ }^{2 *}$ \\ ${ }^{1}$ Department of Agricultural Structures and Irrigation, Faculty of Agriculture, Atatürk University, \\ 25240, Erzurum, Turkey \\ ${ }^{2}$ Department of Landscape Architecture, Faculty of Agriculture, Atatürk University, 25240, Erzurum, \\ Turkey
}

\begin{abstract}
The effects of changes in water use of Tortum Lake watershed were studied. This study investigates the effects of changes in water use culture, and its reflection on landscape during the last 35 years time period. In the last 35 years of time period, factors which caused the changes in type of water use can be discussed and determined under four subjects, which are; (1) fountains constructed built in Tortum Lake watershed by General Directorate of Rural Services (KHGM) in 1975 (2) facilitating the transportation which increased the urban integration, widespread communication, establishing the drinking and usable water systems, (3) changes in water use of traditional agriculture system and establishment of trout production facilities, and (4) establishment of high plateau roads and spreading the recreational activities. From this study, evident changes in (1) structure of cultural and rural landscape (2) sort of traditional architecture (3) type of household water use, were observed. It was found that water resources are contaminated with household pollutants.
\end{abstract}

Key words: Water use culture, rural landscape, Tortum Lake watershed.

\section{INTRODUCTION}

Landscape can be described as the visible expression of the physical, biological and cultural processes occurring in a particular place (Goodwin et al., 2000). A healthy environment (in terms of ecology, soil conservation, hydrological function etc.) is also a highly regarded landscape.

Water has important effects on landforms through sedimentation and erosion, and on the types, quantities and distributions of vegetation, aquatic organisms, and wildlife. Water is also one of the most important and most attractive visual elements of landscape. Visual quality of water is crucial in landscape design and management. In addition, water constructs and completes the river landscape effects. Its clearness, reflections, color and contrasts are the main components of landscape dominancy (Yamashita, 2002). Effective watershed management and planning programs and applications tend to meet the targets of necessity of comfortable, clear water, open area and not complex landscape (Baker et al., 2000).

\footnotetext{
* Corresponding author: Associate Professor, Department of Landscape Architecture, Faculty of Agriculture, Atatürk University, 25240, Erzurum, Turkey, E-mail: fariskarahan@gmail.com

(C) 2009 School of Agriculture and Rural Development, Bangladesh Open University, All rights reserved.
} 
Civilization has been developed parallel to changing process of water use techniques. First settlements were established close to rivers, which enabled to irrigate crops easily. Increased agricultural activities and enlargement of settlements depending on the population necessitated using higher amount of water (Gleick, 2001). However, these changes and developments originated important differences in type of use beyond the influence on water sufficiency. Eventually, these differences change natural and cultural landscape structure.

Human made disasters such as global warming, destruction of rain forests, and over hunting in oceans caused freshwater stress. United Nations reported that 5.1 billion people will be facing serious water stress by the year 2025 (Kulshreshtha, 1998). Perspectives about water stress concern originate from which current 6 billion world population will be over 9 billion by 2050 . Unfortunately, amount of freshwater in the world does not increase. About $97 \%$ of total water in the world exists as salty water in seas and oceans. Nearly $2 \%$ total water in the world is in the form of glacier and under effect of permafrost. Remaining $1 \%$ of water is used for drinking and industrial purposes (Montaigne, 2002).

Turkey's freshwater resources are also under stress as other parts of the world. Human have no sufficient water to meet all demands, in all places and at all times. Declining water qualitylargely as a result of changing land uses is an increasing concern. Freshwater is subject to greater competition than ever before (Demircan, 2002). Two main problems related to water stress are being its insufficient and clearness (Sahsuvaroglu, 2001).

Problems related to water use in rural regions has been appeared in last two decades. During this time, urbanization has been started in Turkey and migration from rural region to cities has continued. People living in rural land desired the attractiveness of city life and this changed water use culture in their houses and environments. This unconscious water consumption began to pollute the environment and water resources. These changes also affected traditional architecture, use of fountains in villages and waste management.

FAO describes water pollution as water having characteristics such as harmful to living organisms, dangerous for human health, obstructing the fishing activities and degrading the water quality (Kayabasi, 1995). Factors causing the water pollution are (1) household waste water, (2) industrial waste water, (3) fertilizers and pesticides for agricultural purposes, (4) erosion and applications for agricultural land improvement, (5) solid waste, (6) radioactive elements, (7) petroleum products and (8) tourism activities.

The objective of this study was to evaluate the effects of changes in water use understanding in rural areas of Tortum Lake Watershed.

\section{MATERIALS AND METHODS}

The study area is located approximately $80-110 \mathrm{~km}$ from northeast of Erzurum, Turkey (Figure 1). Tortum Lake Watershed is located between $41^{\circ} 07^{\prime} 45^{\prime \prime}$ and $41^{\circ} 45^{\prime} 50^{\prime \prime}$ East longitude $40^{\circ}$

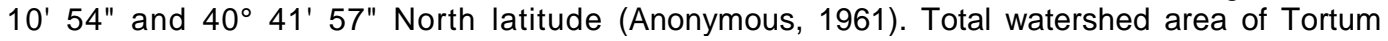
Lake is 179218.40 hectare and of which 560 hectare is Tortum Lake (Guresinli, 1978).

Changes in water use culture of research area and its effects were evaluated in the history frame of 35 year as presented below:

(a) Period before 1975,

(b) Period until first fountains built by General Directorate of Rural Services (KHGM),

(c) 1980 and afterward increase of urban area integration,

(d) Establishing first trout production facility by Turkish Development Foundation in 1990, and

(e) Road construction to plateaus in 2000 and initiation of recreational activities. 

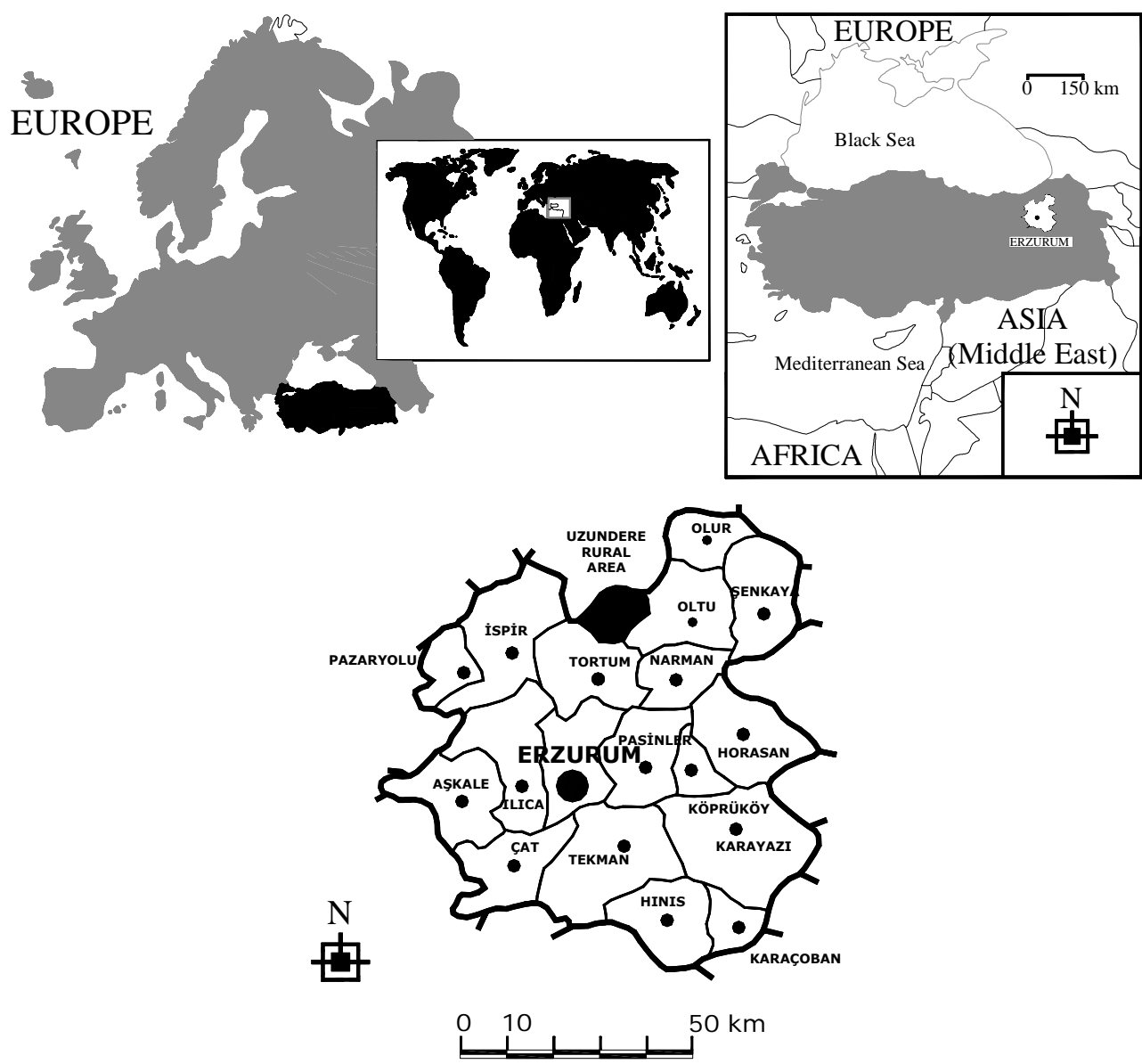

Figure 1. Location of the study area

\section{Results AND Discussion}

\section{Period prior to 1975}

In period prior to 1975 , any urban features were not seen in Tortum Lake watershed. Rural landscape was mostly shaped by agriculture activities. Water was directly provided from creeks for drinking and usage. In this period, various water sources were also used for drinking due to belief that some waters are curative. Water was used traditionally to irrigate fruit and vegetable gardens. There has been no pollution observed in this period due to agricultural and household use. Clay was used for laundry as a cleaning agent. There were no bathroom, toilet, and washbasins in houses. Toilets were located outside of the houses without tap. Wells were digged to collect the sludge from toilets. Sludge's collected from these wells were used as fertilizer.

\section{Building first fountains by KGHM in 1975}

General Directorate of Rural Services (KHGM) brought the first water system to villages in Tortum Lake watershed in 1975. At this time, country people started to leave the habit of providing and transporting water directly from creek for their drinking and use purposes. However, they continued their habit related to laundry and washing dishes until installation was done in houses. Fountains were used very often after harvest to clean up the crops such as wheat, barley. In addition, 
understandings about water use were contents in a big scale as well as traditional construction techniques in this period. Changes based on water use culture started to influence the landscape integrity with mostly (1) development of transportation possibilities, (2) initiation of integration in urban areas and (3) application of new agricultural techniques such as trout production. In this period water use per person was approximately 15 liters per day (personal communication).

In developed countries water use per person is evaluated as 400-500 liters per day. In Turkey water use per person is evaluated as 200-250 liters per day in cities and 100-150 liters per day in rural settlements (Anonymous, 2000). In fact water use per day is approximately 60 liters per person in rural settlements of Turkey. Drinking water statuses of Turkey's rural settlements were given in Table 1.

\section{Initiation of integration in urban areas}

High quality strategic resource management planning and decision making for sustainable development outcomes in water quality management, that: (1) addresses water quality issues, (2) identifies and balances the interests of national, regional and local communities across economic, environmental, cultural and social values, (3) takes a long-term focus, thus considering the needs of current and future generations, (4) identifies complementary strategies, values and interests and recommends actions and solutions that optimize outcomes across values and interests, (5) leads to explicit, transparent and difficult decisions and, where necessary, makes trade-offs between values and (6) inventiveness innovation and relevant research (Anonymous, 2004a).

In many rural settlements in Tortum Watershed, road and electricity were available after 1980. There were not significant changes in water use during this time, but possibilities and attraction of urbanism were started to appear in this time. Generally, improvement of transportation possibilities make migration from villages to cities has momentum. These migrations especially returning their hometown or visiting hometown during holidays resulted in important changes and interaction in social-cultural structure (Karahan, 2004).

Table 1. Drinking water statuses of Turkey's rural settlements (Anonymous, 2000)

\begin{tabular}{|c|c|c|c|c|c|c|c|c|c|c|c|c|}
\hline & \multicolumn{4}{|c|}{ Village } & \multicolumn{4}{|c|}{ Country } & \multicolumn{4}{|c|}{ Total Unit } \\
\hline & Unit & $\%$ & Population & $\%$ & Unit & $\%$ & Population & $\%$ & Unit & $\%$ & Population & $\%$ \\
\hline $\begin{array}{ll}\text { Pipe } \\
\text { 它 } \\
\text { system }\end{array}$ & 19.978 & 27 & 6.562 .092 & 30 & 12.671 & 17 & 1.477 .260 & 20 & 32.649 & 44 & 8.039 .352 & 50 \\
\hline $\begin{array}{ll}\text { Fountain } \\
\text { की } \\
\text { कीstem }\end{array}$ & 9.273 & 12 & 2.916 .486 & 12 & 12.740 & 17 & 1.477 .261 & 21 & 22.013 & 29 & 4.393 .747 & 33 \\
\hline Total & 29.251 & 39 & 9.478 .578 & 42 & 25.411 & 34 & 2.954 .521 & 41 & 54.662 & 73 & 12.433 .099 & 83 \\
\hline $\begin{array}{ll}\frac{+}{\bar{U}} & \text { Pipe } \\
\frac{\mathcal{U}}{U} & \text { system }\end{array}$ & 807 & 1 & 220.954 & 1 & 1.418 & 2 & 121.667 & 3 & 2.225 & 3 & 342.621 & 4 \\
\hline $\begin{array}{l}\text { Fountain } \\
\text { 趌 } \\
\text { ص system }\end{array}$ & 3.088 & 4 & 883.820 & 3 & 3.627 & 5 & 304.170 & 4 & 6.715 & 9 & 1.187 .990 & 7 \\
\hline$=\frac{T}{\text { Total }}$ & 3.895 & 5 & 1.104 .774 & 4 & 5.045 & 7 & 425.837 & 7 & 8.940 & 12 & 1.530 .611 & 11 \\
\hline Without service & 1.406 & 2 & 293.489 & 2 & 9.931 & 13 & 554.941 & 4 & 11.337 & 15 & 848.430 & 6 \\
\hline TOTAL & 34.552 & 46 & 10.876 .841 & 48 & 40.387 & 54 & 3.935 .299 & 52 & 74.939 & 100 & 14.812 .140 & 100 \\
\hline
\end{tabular}

Unretumable changes and degradation of water use types on landscape as whole were started to be seen at the end of 1990. Novelties which can be evaluated as negative way happened in term of effects on landscape structure in socio-economical and cultural structure of Tortum Lake watershed based on transportation, communication, urban attraction and changes in agricultural culture.

Distribution of water from general water system made it available in this period in Tortum Lake watershed. This novelty made fundamental changes in traditional house formation. Traditional stone, soil and wooden constructed village houses were unfavorably affected. Changes both interior and exterior of houses created significant problems in landscape integrity. Wealthy 
families demolished their traditional houses and built new houses having toilet, bathroom, and kitchen inside like an apartment flat. Those who could not afford to do it add kitchen washbasin and bathroom to their house and rebuilt toilet close to house. These changes present new product which is household waste water for Tortum Lake watershed. Waste water is discharged to creeks without any regulation. This situation even gets worse for creek landscape when waste water combined with solid waste from household.

\section{Establishing trout production facilities by Turkish Development Foundation}

Turkish Development Foundation was pioneer to establish first trout production facility in Tortum Lake Watershed in 1990. Water used for trout production was directly provided from main source in the Tortum Lake watershed. Great deal of discussion was started about creek running inside the villages with the starting to-trout production. One of the important results of trout production was that drinking water no more was provided from the creeks. People think that organic feeds used for trout production pollute the creek water, thus, they give up using creek water for their needs.

\section{Road construction to plateaus and initiation of recreational activities}

The value of freshwater for recreation depends on the needs of various recreational activities. These range from low-cost, low-energy, low-skill-required, convenient activities that do not require specific water qualities (eg, picnicking or walking beside a lake), to activities that are relatively higher cost, require a high level of technical skill and equipment, and are more expensive and time demanding (eg, white-water kayaking). The latter activities often require more specific water body conditions, such as high water quality, rapids, gear set-up areas, or good-sized fish (Anonymous, 2004b).

Road construction to plateaus and improvement of recreational activities in Tortum Lake Watershed was done in the last 5 years. It is too early to evaluate the recreational activities. In addition, it is difficult to say that eventually it will not be affected along with constructions in plateau and water pollution and its reflection to landscape.

There is often a strong relationship between good aesthetic landscape outcomes and good land management practices. Land management is responsive to the varying soils, aspects, and slope and drainage patterns in a landscape. Where land uses reflect these underlying natural elements, the resulting landscape patterns generally have high amenity. One example is riparian planting, which improves water quality, conserves soil, and visually emphasizes the drainage pattern in the landscape (Koc and Sahin, 1999; Goodwin et al., 2000).

Landscape can be defined as a heterogeneous area composed of different ecosystems, or a mosaic of patches of different type (landscape elements). During unnatural periods to landscape, affecting any activity can degrade the integrity. Water is always the most vivid and dynamic component of landscape. In developing countries, having water as well as the lack of water appears to be important character influencing the socio-economic and cultural structure, landscape integrity. Important point seen in the research area is how water is going to be used and how it is going to be discharged after use. Socio-economic changes and degenerations create many water related problems as being in natural resources. This period happens too fast that even many natural thoughts leave sort of traditional architecture and degenerate rural landscape integrity without any regain. To solve these problems, following solutions can be advised;

1. Water is a limited resource. It must be provided in a rational way and based on management plan of watershed.

2. People who live in Tortum Lake watershed should be educated about how to use water and informed about water pollution which can affect human, animal, flora, and consequently nature.

3. Household waste water is discharged to creeks without any control. Same problem occurs almost in every village settlements in Tortum Lake watershed. Therefore; sewerage system should be established to collect wastewater and permit discharge of wastewater to Tortum Lake. 
4. Management plans should be prepared for future houses in plateaus, tourism, forestry, animal husbandry and not be allowed the pressure on water resources to affect landscape integrity.

5. Research area carries an important role in terms of eco-tourism for now and future. Conscious of protection for natural landscape properties of region (forest vegetations, alpine pasture, creek vegetations) and cultural resources (grape and garden culture, traditional structure examples) historical places (Osvank and Haho Churches) should be evaluated. Sustainability of this character is dependent on providing clear, lasting and plenty of water which is dynamic and complementary component of landscape.

During period of full membership to European Union, financial supports for projects related to environment, tourism, forestry, agriculture and planning and management of sustainability of water resources for Tortum Lake Watershed from European Union Donation Funds would be beneficial for Erzurum-Erzincan-Bayburt provinces, Turkey.

\section{Literature Cited}

Anonymous. 1961. Geological Map of Turkey (Trabzon Region). Ankara.

Anonymous. 2000. VIII. Development Plan for 5 year period (2001-2005). Drinking water, sewerage, treatment and solid waste management special commission report. State Planning Organization of Turkey (DPT), Ankara.

Anonymous. 2004a. Water Programme of Action: The Effects of Rural Land Use on Water Quality. Ministry for the Environment Press. Wellington, New Zealand.

Anonymous. 2004b. Water Bodies of National Importance Potential Water Bodies of National Importance for Recreation Value. Ministry for the Environment Press, Wellington, New Zealand.

Baker, M.B., Folliott, P.F., Edminster, C.B., Mora, K.L. and Dillon, M.C. 2000. Watershed Management Contributions to Land Stewardship: A Literature Review. General Technical Report RMRS-GTR-71WWW. Fort Collins, CO: U.S. Department of Agriculture, Forest Service, Rocky Mountain Research Station.

Demircan, S. 2002. Water for who?. In "National Geographic Turkey", 17, 100-105.

Gleick, P.H. 2001. Water. In "TUBITAK Science and Technical Journal" 401, 32-34.

Goodwin, J., de Lambert, R., Dawson, S., McMahon, S. and Rackham, A. 2000. The Impact of Development on Rural Landscape Values. Ministry for the Environment Press, Wellington, New Zealand.

Guresinli, Y.Z. 1978. A Research on Erosion Problem and its Control in Tortum Watershed. PhD Thesis. Ataturk University, Erzurum, Turkey.

Karahan, F. 2004. Traditional houses in Tortum watershed: responsibilities in conserving cultural landscape and traditional architecture. Yearbook of Rural Environment, Ankara, Turkey, pp. 34-41.

Kayabasi, Y. 1995. Pollution of water resources. In "Turk J. of Agric. and Village", 103, 24-25.

Koc, N. and Sahin, S. 1999. Rural Landscape Planning. Ankara University Press, Ankara, Turkey.

Kulshreshtha, S.N., 1998. A Global Outlook for Water Resources to the Year 2025. In "Water Resources Management", 12(3), 167-184.

Montaigne, F. 2002. Power of water. In "National Geographic Turkey" 17, 68-99.

Sahsuvaroglu, L. 2001. Dimensions of soil-water management and strategic approach. In "Turk J. of Agric. and Village" 138, 8-10.

Yamashita, S. 2002. Perception and evaluation of water in landscape: use of photo-projective method to compare child and adult residents' perceptions of a Japanese river environment. In "Landscape and Urban Planning", 62, 3-17. 